\title{
Postural instability and falls are more frequent in Parkinson's disease patients with worse trunk mobility
}

\author{
Instabilidade postural e quedas são mais frequentes em pacientes com doença de \\ Parkinson com pior mobilidade de tronco
}

Nathalie Ribeiro Artigas ${ }^{1}$, Clarissa Franco', Paula Leão', Carlos R. M. Rieder

\begin{abstract}
Postural instability and axial rigidity are frequent symptoms of the Parkinson's disease (PD). Objective: Correlate the occurrence of falls and the activity of rolling over in bed with performance on the Trunk Mobility Scale (TMS) in patients with PD, and determine whether this instrument score can predict the risk of falls. Method: This is a cross-sectional study. Assessed patients reported the frequency of falls in the previous year and whether they had difficulties rolling over in bed. Then, the following scales were applied: TMS, Hoehn and Yahr, Unified Parkinson's Disease Rating Scale-III and Schwab and England Activities of Daily Living. Results: Eighty-five patients were analyzed. Patients with a history of falling showed worse performance in the TMS ( $p<0.01)$. There is a significant correlation between TMS and the activity of rolling over in bed $(p<0.01)$. Conclusion: PD fallers present worse scores in TMS, and there is a significant correlation between difficulty rolling over in bed and TMS score.
\end{abstract}

Keywords: Parkinson disease; accidental falls; mobility limitation; postural balance.

\section{RESUMO}

A instabilidade postural e a rigidez axial são sintomas frequentes da doença de Parkinson (DP). Objetivo: Correlacionar a ocorrência de quedas e a atividade de rolar na cama com o desempenho na Escala de Mobilidade de Tronco (TMS) entre os pacientes com DP e verificar se esse instrumento pode prever o risco de quedas. Metodo: Trata-se de um estudo transversal onde os pacientes avaliados relataram a frequência de quedas no ano anterior e as suas dificuldades para rolar na cama. Em seguida as seguintes escalas foram aplicadas: TMS, Hoehn and Yahr, Escala Unificada da Doença de Parkinson-III e Escala Schwab e England. Resultados: 85 pacientes foram avaliados. Os pacientes que possuíam histórico de quedas apresentaram pior desempenho no TMS ( $p<0,01)$. Há uma correlação significativa entre a TMS e a atividade de rolar na cama $(p<0,01)$. Conclusão: Pacientes que relataram quedas apresentam pior pontuação no TMS e há uma correlação significativa entre a dificuldade de rolar na cama e o TMS.

Palavras-chave: doença de Parkinson; acidentes por quedas; limitação de mobilidade; equilíbrio postural.

Postural instability and falls are common in Parkinson's disease (PD), mainly in advanced stages of the disease. Falls are rare in the first two years of PD, and if they occur in this phase, they suggest an alternative diagnosis ${ }^{1}$. Individuals with $\mathrm{PD}$ and Hoehn and Yahr (H\&Y) stages 1 to 5 usually present increased postural instability and walking alterations that result in more frequent falls than in people of the same age without the pathology².

A study that evaluated the clinical impact and the risk of falls in 59 patients with PD observed that over 200 falls occurred in 6 months. Of these patients, $50 \%$ fell at least once, and $35 \%$ experienced recurring falls with associated lesions ${ }^{3}$.
Falls in PD are usually related to the type of activity performed by the patient. They occur more frequently when the patient, for instance, tries to change direction while walking, at the start of walking and after standing up ${ }^{4,5}$. The occurrence of falls is also significantly related to a higher level of cognitive impairment among individuals with $\mathrm{PD}^{6}$.

Some authors believe that the proper control of trunk movement is very important for postural stability because the upper part of the body is responsible for $2 / 3$ of the body weight and for its center of gravity ${ }^{4,7}$. Recent studies have confirmed the important contribution of the proximal

${ }^{1}$ Universidade Federal do Rio Grande do Sul, Programa de Pós-graduação em Ciências Médicas, Porto Alegre RS, Brasil;

${ }^{2}$ Centro Universitário Metodista do IPA, Porto Alegre RS, Brasil;

${ }^{3}$ Universidade Federal de Ciências da Saúde de Porto Alegre, Departamento de Clínica Médica, Neurologia, Porto Alegre RS, Brasil.

Correspondence: Nathalie Ribeiro Artigas; Santa Luzia, 337; 94185-330 Gravataí RS, Brasil; E-mail: nathalie.artigas@gmail.com

Conflict of interest: There is no conflict of interest to declare.

Received 19 August 2015; Received in final form 26 March 2016 ; Accepted 06 april 2016. 
musculature to normal balance and to the occurrence of falls. Despite evidence of loss of trunk control in PD (for instance, while walking, in posture transference and in the sitting position), few studies have examined the effects of PD on the postural reaction of the proximal musculature ${ }^{8}$.

It is also known that patients with PD present limited trunk flexibility due to axial rigidity, which is reflected in the co-contraction of hip and trunk muscles, leading to impaired selectivity and movement coordination that affects balance $^{8,9,10}$. All these factors would significantly influence the quality of life of these people.

It is very difficult to predict which patients are at higher risk of falls. The occurrence of previous falls and a moderate severity of PD (H\&Y - stage 3) are more consistent and independently associated with the probability of falling. Other predictive factors are fear of falling, daily intake of alcohol and current use of benzodiazepine ${ }^{11,12}$.

Usually, the pull test and the push test are used to assess the risk of falls, but some studies have suggested that these tests are not particularly effective for predicting postural instability and falls ${ }^{11,12}$. Additionally, there are few studies that effectively evaluate trunk rigidity in these patients; this is not a directly evaluated aspect even in the Unified Parkinson's Disease Rating Scale-III (UPDRS-III). In a previous study, we found that the Trunk Mobility Scale (TMS) ${ }^{13}$ is a practical, complete (assessing all planes of axial musculature movement) and efficient tool for clinically evaluating the trunk mobility of PD patients; thus, it can monitor the changes due to medication and/or physiotherapeutic treatment. Falls are related to reduced trunk mobility in individuals with $\mathrm{PD}^{8,9,10}$, but little is known about axial tone in PD patients or the relationship between axial rigidity and functional impairment. This study aimed to evaluate the association of falls with a scale (TMS) recently developed by our group, to determine the potential of this scale for predicting risk of falls and to help develop methods to prevent falls in PD patients.

Therefore, the purpose of this study was to correlate the occurrence of falls with the TMS scores of PD patients. This determines whether the TMS tool can predict the risk of falls. We also assess the relationships between the occurrence of falls, TMS and reports of difficulties with rolling over in bed.

\section{METHOD}

The study involved 85 patients with a diagnosis of Parkinson's disease, according to the criteria of the UK Parkinson's Disease Society Brain Bank ${ }^{14}$. Patients were recruited from the Movement Disorder Clinic. All participants who agreed to participate in the study signed an informed consent form and were scheduled for the procedure.

Exclusion criteria were as follows: Patients in an off-medication period with a diagnosis of other neurological pathologies (ataxia, cerebral vascular accident, Alzheimer's disease, dementias), those with orthopedic surgeries (column arthrodesis at any level) and those with diagnosed traumatic and orthopedic diseases (fracture, arthrosis) that prevented the tests from being performed were excluded.

\section{Procedures}

An assessment was performed to verify: age, gender, time since diagnosis, description of rolling over in bed and the occurrence of falls in the previous year. We applied the $\mathrm{TMS}^{13}$, H\&Y $Y^{15}$, UPDRS-III ${ }^{16}$ and Schwab and England Activities of Daily Living $(S \& E)^{17}$. All ratings were performed one hour after use of antiparkinsonian medication with patients in the ON moment. The clinical characteristics of the sample are described in Table 1.

The TMS is composed of six dynamic tests that involve the trunk movements in the sagittal plane (stretching/flexion), transversal (rotation) and frontal (side inclination) and one static test that evaluated the posture at the sitting position. The tests were performed with the patient sitting on a chair, with no arm support, feet on the floor and the back kept $10 \mathrm{~cm}$ from the chair. All movements were demonstrated to the patient.

Scores of dynamic items ranged from 0 (patient makes the movement without any compensation) to 3 (patient is unable to make the requested movement). Score 2 is attributed to the movement being performed with great compensation ( for instance, when inclining sideways, the patient associates trunk rotation, flexion and/or stretching movements). For small compensations, score 1 is assigned. Each task considers specific associated movements that would be alterations to the movement requested in each plane.

Great compensations are exaggerated movements, easily noticed by an investigator. Small compensations are subtle movements, but they are present when the movement is performed.

In the static aspect, the sitting position analysis may range from 4 (strong flexion and/or side inclination with extreme posture abnormality) to 0 (upright sitting position).

In terms of rolling over in bed, the patients had to select the description that best corresponded to their performance among the following 4 options:

- performs the movement with no difficulty;

- performs the movement with difficulty, needs some push;

- performs the movement only with their hands supported on the bed;

- cannot perform the movement without the help of others.

Table 1. Clinical characteristics of patients.

\begin{tabular}{lccc} 
Variable & $\begin{array}{c}\text { Parkinson } \\
(n=85)\end{array}$ & $\begin{array}{c}\text { Falls } \\
(n=29)\end{array}$ & $\begin{array}{c}\text { No falls } \\
(n=56)\end{array}$ \\
\hline Age & $67.25( \pm 11.21)$ & $68.77( \pm 10.23)$ & $66.58( \pm 11.63)$ \\
Diagnosis (years) & $7.78( \pm 4.89)$ & $8.15( \pm 5.27)$ & $7.61( \pm 4.76)$ \\
Gender & & & \\
$\quad$ female & $43(50.60 \%)$ & $15(51.70 \%)$ & $28(50 \%)$ \\
$\quad$ male & $42(49.40 \%)$ & $14(48.30 \%)$ & $28(50 \%)$ \\
\hline
\end{tabular}


All patients signed a consent form. The study was approved by the Ethics Committee.

\section{Statistical analysis}

The category variables were described through absolute and relative frequencies. The quantitative variables were described through mean and standard deviation. The inferential analysis used Fisher's Exact test (for the following variables: 'rolling over in bed' versus 'falls'), the chi-squared test (for 'TMS cut-off point' versus 'falls'), Student's t-test (for 'falls' versus 'scores in scales') and Spearman's correlation coefficient ( for the correlation between the scales and 'rolling over in bed'). The measurement of the predictive value of falls employed the ROC curve.

The significance level adopted in the study was $\mathrm{p}<0.05$.

\section{RESULTS}

Falls occurred in 29 patients (34.12\%). Fallers presented worse performance in TMS (9.72 \pm 5.26 and $5.34 \pm 3.82$; $\mathrm{p}<0.01)$ and always had the worst scores in other evaluated scales $(\mathrm{p}<0.01)$.

The sample was divided into two groups: patients who rolled over in bed with no difficulty $(38.80 \%)$ and patients who could roll over in bed only with their hands supported on the bed (42.40\%). The other options - needs some push and cannot roll without the help of others - were less frequently chosen (4.70\% and $14.10 \%$, respectively). The analysis of rolling over in bed did not show any significant difference between fallers and non-fallers (Fischer's exact test, $\mathrm{p}=0.070$ ). The performance in the scales are described in Table 2.

The correlation between the evaluated scales and rolling over in bed was significant $(\mathrm{p}<0.01)$; patients with greater difficulty rolling over in bed presented worse scores in the scales UPDRS, H\&Y, S\&E and TMS $\left(\mathrm{r}_{\mathrm{s}}=0.53 ; \mathrm{r}_{\mathrm{s}}=0.51 ; \mathrm{r}_{\mathrm{s}}=-0.48\right.$; $r_{s}=0.48$, respectively).

We also verified that the TMS shows a sensitivity of $38.50 \%$, in terms of falls, and the specificity was $78 \%$, both considering scores of 7 or less. The ROC curve presented an area of 0.74 (CI95\%: 0.62-0.86; $\mathrm{p}<0.01$ ) (Figure). The ratio of prevalence was $3.01(\mathrm{CI} 95 \%=1.69-5.37)$. The calculation of positive predictive value was $55.17 \%$, and negative predictive value was $82.14 \%$.

\section{DISCUSSION}

Patients with PD have great difficulty maintaining balance and frequently fall. This difficulty is a result of the combination of several deficiencies, including loss of reflexes and postural adjustments, the rigidity of the trunk/ends and akinesia ${ }^{18,19,20}$. Marck et al. ${ }^{21}$ described and analyzed 31 falls risk factors in PD and identified 16 generic risk factors and 15 PD-specific risk factors. This author says that the routine evaluation of all risk factors remains reserved for high-risk patients without prior falls, or for patients with seemingly unexplained falls.

Burg et al. $^{4}$ found a $75 \%$ fall rate caused by PD patients' inability to control their center of mass. They also say that the lack of trunk movement coordination may increase the risk of unbalance and falls. Kimmell et al. ${ }^{22}$ agrees with this finding because, in his study, the subjects fell because they did not take a step in the direction of pull to maintain their center of mass over their feet, thus indicating a deficiency in postural reflexes.

In this study, we noticed that fallers had worse performance in TMS compared to non-fallers (9.72 and 5.36; $\mathrm{p}<0.01$ ), and they had the worst scores in other PD evaluation scales as well (H\&Y, UPDRS-III and S\&E). Accordingly,

Table 2. Performance in the scales.

\begin{tabular}{|c|c|c|c|}
\hline Variable & Parkinson $(n=85)$ & Falls $(n=29)$ & No falls $(n=56)$ \\
\hline Trunk Mobility Scale & $6.75( \pm 4.92)$ & $9.72( \pm 5.26)^{*}$ & $5.34( \pm 3.82)^{\star}$ \\
\hline UPDRS-III & $29.15( \pm 22.47)$ & $47.00( \pm 24.09)^{\star}$ & $24.13( \pm 19.58)^{\star}$ \\
\hline S\&E & $80.47( \pm 18.95)$ & $65.86( \pm 22.12)^{*}$ & $86.61( \pm 14.18)^{\star}$ \\
\hline H\&Y & $2.59( \pm 1.05)$ & $3.33(0.98)^{\star}$ & $2.29(0.99)^{\star}$ \\
\hline 1 & 7 & 0 & 7 \\
\hline 1.5 & 8 & 1 & 7 \\
\hline 2 & 19 & 4 & 15 \\
\hline 2.5 & 18 & 5 & 13 \\
\hline 3 & 15 & 4 & 11 \\
\hline 4 & 15 & 12 & 3 \\
\hline 5 & 3 & 3 & 0 \\
\hline \multicolumn{4}{|l|}{ Rolling over in bed } \\
\hline No difficulty & $38.80 \%$ & $44.60 \%$ & $27.60 \%$ \\
\hline Needs some push & $4.70 \%$ & $5.40 \%$ & $3.40 \%$ \\
\hline Hands supported on bed & $42.40 \%$ & $42.90 \%$ & $41.40 \%$ \\
\hline Only with the help of others & $14.10 \%$ & $7.10 \%$ & $27.60 \%$ \\
\hline
\end{tabular}

UPDRS-III: unified Parkinson's disease rating scale-III; S\&E: Schwab and England activities of daily living; H\&Y: Hoehn and Yahr; *t-test: $p<0.01$ 


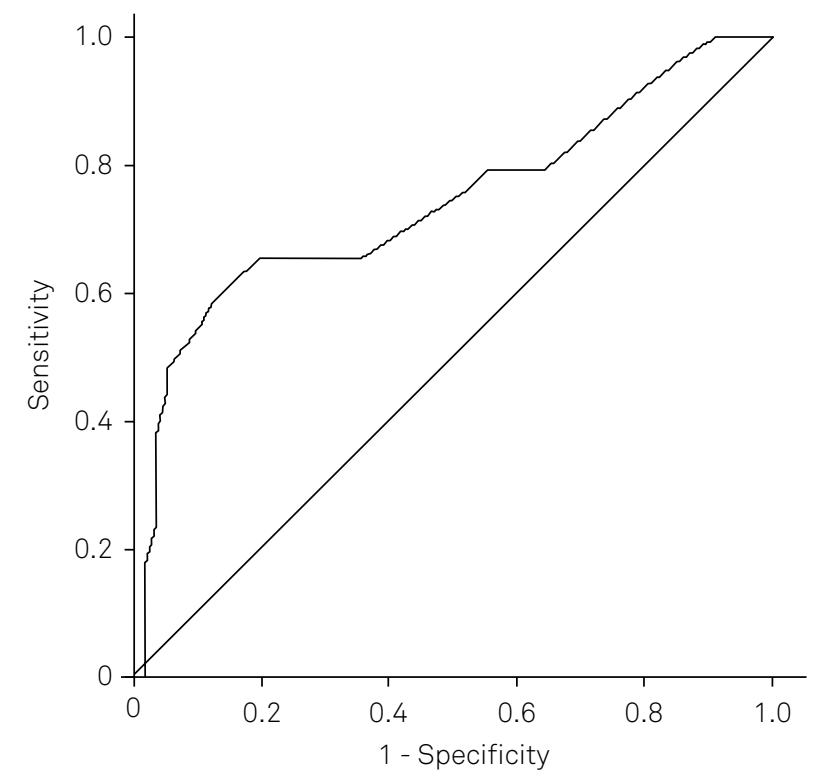

Figure. ROC courve: diagonal segments are produced by ties.

we can conclude that according to the literature, the worse the disease, the worse the trunk mobility and the higher the risk of falls. To assess the functionality of patients, we correlated their scores in TMS with a variable that could express a daily activity (the report on the difficulty with rolling over in bed). The results showed correlation between these two variables $\left(r_{s}=0.48 ; p<0.01\right)$. Thus, we can say that the patients with greater difficulty rolling over in bed present very degraded trunk mobility.

When correlating the variable 'rolling over in bed' with the scales H\&Y, S\&E and UPDRS-III, the worst scores were also presented by those with greater difficulty rolling over in bed $\left(r_{s}=0.51 ; r_{s}=-0.48\right.$ and $r_{s}=0.53$, respectively; $\left.p<0.01\right)$. Considering that such scales evaluate PD staging, functional inability and intensity of motor symptoms, we can say that the patients who poorly perform in the activity of rolling over in bed usually present an advanced stage of the disease, and they report greater difficulty with daily activities and more severe motor symptoms.

Functional movements require the combined mobility of several parts of the body. Mobility in bed, for instance, involves thorax rotation relative to the pelvis ${ }^{23}$. Thus, we suggest that fallers are likely to experience greater difficulty in performing daily activities.

Our data support this hypothesis as the proportion of fallers who also presented great difficulty rolling over in bed was higher than in non-fallers (27.60\% and $7.10 \%$, respectively). On the other hand, the rate of non-fallers who also could roll over in bed easily was higher than in fallers $(44.60 \%$ and $27.60 \%$, respectively). That is, according to our predictions, fallers present greater difficulty with performing daily activities.

The main results of this study are in agreement with the findings of Cano-de-la-Cuerda et al. ${ }^{24}$, who used an isokinetic dynamometer to assess trunk rigidity in $36 \mathrm{PD}$ patients.
The authors concluded that trunk rigidity is correlated with disease severity, disease duration, functional status and quality of life in PD patients.

Bloem et al. ${ }^{3}$ verified in a previous study that the best way to predict the occurrence of falls is to use a combination of factors, including the following: questioning about previous falls, severity of the disease and Romberg's test. Although the specificity of this combination was excellent (98\%), the general diagnostic sensitivity was negatively affected (65\%), indicating a substantial proportion of patients who presented recurrent falls, but who had not been diagnosed. Because falls may cause injuries and may require therapeutic intervention, a high-sensitivity test (perhaps allowing a lower specificity) would be preferable.

We verified that the TMS sensitivity, in terms of falls, is $61.50 \%$, by considering scores of 8 or over. This result means that patients presenting a score of 7 in TMS will have a low chance of falling. We also calculated the ratio of prevalence, which was $3.01(95 \% \mathrm{CI}=1.69-5.37)$. That is, the prevalence of falls in patients presenting scores of 8 or higher is 3.01 greater than in those with TMS scores of 7 or lower.

In TMS the positive predictive value for falls was $55.17 \%$, and the negative predictive value was $82.14 \%$. This result is probably related to the worsening of motor symptoms that occur with the progression of the disease. Some authors defend the idea that the main mechanism involved in the loss of trunk mobility in PD is axial rigidity ${ }^{10,25}$. The relevance of axial tone to functional impairment in walking, balance and motor control is widely described in many studies ${ }^{26}$.

Regarding the TMS specificity for falls, the value of 78\% was verified for scores of 7 or less, which is a very high specificity. These values were already expected because the scale was intended to directly assess neither balance nor the falls, but to measure one of its determinant factors: trunk mobility.

The TMS scale was used in the present study because it was developed and validated by our group and we were interested in know how this scale could contribute to evaluate the association with falling. Our findings confirm that the fallers show greater difficulty with rolling over in bed and have worse TMS scores. There are other scales for the trunk movement assessment in patients with PD include the functional rotation test ${ }^{27}$ and the functional axial rotation ${ }^{28}$. However, both scales require a special infrastructure and the trunk flexion measurement is not part of any integrated scale that quantifies the two movement planes in a single instrument. Future studies are needed to verify the trunk mobility in larger populations and the relationship between the TMS results with other scales and evaluation tests of motor capacity and falls.

We conclude that PD fallers show greater difficulty with rolling over in bed and have worse trunk mobility when assessed by TMS scale. TMS is a sensitive tool for detecting the risk of falls, and we believe that it is a helpful instrument for the functional assessment of patients. The scale reflects information that is directly linked to the quality of life of the patient. 
1. Mactier K, Lord S, Godfrey A, Burn D, Rochester L. The relationship between real world ambulatory activity and falls in incident Parkinson's disease: influence of classification scheme. Parkinsonism Relat Disord. 2014;21(3):236-42. doi:10.1016/j.parkreldis.2014.12.014

2. Kegelmeyer DA, Kloos AD, Thomas KM, Kostyk SK. Reliability and validity of the Tinetti Mobility Test for individuals with Parkinson disease. Phys Ther. 2007;87(10):1369-78. doi:10.2522/ptj.20070007

3. Bloem BR, Grimbergen YAM, Cramer M, Willemsen M, Zwinderman AH. Prospective assessment of falls in Parkinson's disease.J Neurol. 2001;248(11):950-8. doi:10.1007/s004150170047

4. Burg JCE, Wegen EEH, Rietberg MB, Kwakkel G, Dieën JH. Postural control of the trunk during unstable sitting in Parkinson's disease. Parkinsonism Relat Disord. 2006;12(8):492-8. doi:10.1016/j.parkreldis.2006.06.007

5. Alexandrov A, Aurenty R, Massion J, Mesure S, Viallet F. Axial synergies in parkinsonian patients during voluntary trunk bending. Gait Posture. 1998;8(2):124-35. doi:10.1016/S0966-6362(98)00026-5

6. Amar K, Stack E, Fitton C, Ashburn A, Roberts HC. Fall frequency, predicting falls and participating in falls research: similarities among people with Parkinson's disease with and without cognitive impairment. Parkinsonism Relat Disord. 2015;21(1):55-60. doi:10.1016/j.parkreldis.2014.11.001

7. Nikfekr E, Kerr K, Attfield S, Playford DE. Trunk movement in Parkinson's disease during rising from seated position. Mov Disord. 2002;17(2):274-82. doi:10.1002/mds.10073

8. Carpenter MG, Allum JHJ, Honegger F, Adkin AL, Bloem BR. Postural abnormalities to multidirectional stance perturbations in Parkinson's disease. J Neurol Neurosurg Psychiatry. 2004;75(9):1245-54. doi:10.1136/jnnp.2003.021147

9. Horak FB, Dimitrova D, Nutt JG. Direction-specific postural instability in subjects with Parkinson's disease. Exp Neurol. 2005;193:504-21. 10.1016/j.expneurol.2004.12.008

10. Van Emmerik REA, Wagenaar RC, Winogrodzka A, Wolters EC. Identification of axial rigidity during locomotion in Parkinson disease. Arch Phys Med Rehabil. 1999;80(2):186-91. doi:10.1016/S0003-9993(99)90119-3

11. Ashburn A, Stack E, Pickering RM, Ward CD. Predicting fallers in a community-based sample of people with Parkinson's disease. Gerontology. 2001;47(5):277-81. doi:10.1159/000052812

12. Nonnekes J, Goselink R, Weerdesteyn V, Bloem BR. The retropulsion test: a good evaluation of postural instability in Parkinson's disease? J Parkinsons Dis. 2015;5(1):43-7.

13. Franco CR, Leão P, Townsend R, Rieder CR. Reliability and validity of a scale for measurement of trunk mobility in Parkinson's disease: Trunk Mobility Scale. Arq Neuropsiquiatr. 2011;69(4):636-41. doi:10.1590/S0004-282X2011000500012

14. Hughes AJ, Daniel SE, Kilford L, Lees AJ. Accuracy of clinical diagnosis of idiopathic Parkinsosn's disease: a clinico-pathological study of 100 cases. J Neurol Neurosurg Psychiatr. 1992;55:181-4. doi:10.1136/jnnp.55.3.181
15. Hoehn MM, Yahr MD. Parkinsonism: onset, progression and mortality. Neurology. 1967;17(5):427-42. doi:10.1212/WNL.17.5.427

16. Fahn S, Elton RL. Unified Parkinson's disease rating scale. In: Fahn S, Marsden CD, Calne D, Goldstein M. Recent developments in Parkinson's disease. Florham Park, NJ: Macmillan Healthcare Information; 1987. p. 153-63.

17. Martinez-Martín P, Gil-Nagel A, Gracia LM, Gómez JB, Martínez-Sarriés J, Bermejo F. Unified Parkinson's disease rating scale characteristics and structure. Mov Disord. 1994;9(1):76-83. doi:10.1002/mds.870090112

18. Qutubuddin AA, Pegg PO, Cifu DX, Brown R, McNamee S, Carne W. Validating the Berg Balance Scale for patients with Parkinson's disease: a key to rehabilitation evaluation. Arch Phys Med Rehabil. 2005;86:789-92. doi:10.1016/j.apmr.2004.11.005

19. Bloem BR, Steijns JAG, Smits-Engelsman BCM. An update on falls. Curr Opin Neurol. 2003;16(1):15-26. doi:10.1097/00019052-200302000-00003

20. Grimbergen YA, Schrag A, Mazibrada G, Borm GF, Bloem BR. Impact of falls and fear of falling on health-related quality of life in patients with Parkinson's disease. J Parkinsons Dis. 2013;3(3):409-13. doi:10.3233/JPD-120113

21. Marck MA, Klok MP, Okun MS, Giladi N, Munneke M, Bloem BR. Consensus-based clinical practice recommendations for the examination and management of falls in patients with Parkinson's disease. Parkinsonism Relat Disord. 2014;20(4):360-9. doi 10.1016/j.parkreldis.2013.10.030

22. Kimmell K, Pulusu VK, Bharucha KJ, Ross ED. Postural instability in Parkinson disease: to step or not to step.J Neurol Sci. 2015;357(1-2):146-51. doi:10.1016/j.jns.2015.07.020

23. Schenkman M, Shipp KM, Chandler J, Studenski SA, Kuchibhatla M. Relationships between mobility of axial structures and physical performance. Phys Ther. 1996;76(3):276-85.

24. Cano-de-la-Cuerda R, Vela-Desojo L, Miangolarra-Page JC, Macías-Macías Y. Isokinetic dynamometry as a technologic assessment tool for trunk rigidity in Parkinson's disease patients. NeuroRehabilitation. 2014;35(3):493-501. doi:10.3233/NRE-141142

25. Van Vaerenbergh J, Vranken R, Baro F. The influence of rotational exercises on freezing in Parkinson's disease. Funct Neurol. 2003;18(1):11-6.

26. Wright WG, Gurfinkel VS, Nutt J, Horak FB, Cordo PJ. Axial hypertonicity in Parkinson's disease: direct measurements of trunk and hip torque. Exp Neurol. 2007;208(1):38-46. doi:10.1016/j.expneurol.2007.07.002

27. Batavia M, Gianutsos JG. Test-retest reliability of the seated Functional Rotation Test in people with Parkinson's disease: a preliminary study. Percept Mot Skills. 2004;99(1):259-70. doi:10.2466/pms.99.1.259-270

28. Schenkman ML, Clark K, Xie T, Kuchibhatla M, Shinberg M, Ray L. Spinal movement and performance of a standing reach task in participants with and without Parkinson disease. Phys Ther. 2001;81(8):1400-11. 